\title{
CONCEITOS E MÉTODOS DE ANÁLISE DO CAMPO ARTÍSTICO
}

Maria Lúcia Bastos Kern*

SÍNTESE - O presente estudo tem em vista retomar os conceitos desenvolvidos por Pierre Bourdieu para a análise do sistema de relações objetivas que se desenvolvem no interior do campo artístico e os fundamentos teóricos que medeiam a atuação do artista como agente social e indivíduo. Para tal, o estudo será baseado apenas nos textos que se centralizam nas problemáticas especificas do campo artístico, apesar da numerosa e significativa produção publicada pelo mencionado sociólogo de 1958 a 1995.

\begin{abstract}
The present study intends to retake the main concepts developed by Pierre Bourdieu to the analysis of the system of objective relations developed insides of the artistic area and the theoretic bases that make a mediation of the artist's actuation as a social agent and individual. On account of that, the study will be based just on the texts centralized in the specific problems of the artistic area, although the numerous and significant production published by the mentioned sociologist since 1958 until 1995.
\end{abstract}

\section{1 - Introdução}

O presente estudo tem em vista retomar os principais conceitos desenvolvidos por Pierre Bourdieu para a análise do sistema de relações objetivas que se desenvolvem no interior do campo artístico e os fundamentos teóricos que mediam a atuação do artista como agente social e indivíduo. Para tal, o estudo será baseado apenas nos textos que se centralizam nas problemáticas específicas do campo artístico, ${ }^{1}$ apesar da numerosa e significativa produção publicada pelo mencionado sociólogo de 1958 a $1995^{2}$

A produção intelectual de Bourdieu caracteriza-se pelo desenvolvimento de um pensamento social crítico, tendo como fundamentação uma vasta e testada pesquisa empírica, que visa analisar e tornar transparentes os fenômenos e as regras que orientam as relações sociais. Esta conduta dirigida à transparência da construção social faz com que o seu papel não se limite apenas à função de cien-

* Professora da Pontifícia Universidade Católica do Rio Grande do Sul, PUCRS.

1 De forma mais especifica os textos que se referem às artes plásticas. Economia das tocas simbólicas; O poder simbólico; L'Amour de l'art, publicado com Darbel e Schnapper; La distinction - critique sociale du jugement; Règles de l'art; Libre - échange, escrito com o artista plástico Hans Haacke.

2343 publicações segundo CHAUVIRE, C. In: Critique, ag./set. 1995. p. 547.

\begin{tabular}{|l|l|l|l|l|l|}
\hline VERITAS & Porto Alegre & v. 41 & $\mathrm{n}^{\circ} 162$ & Junho 1996 & p. 229-236 \\
\hline
\end{tabular}


tista social mas também ao exercício de militância, procurando esclarecer os agentes sociais desprovidos de poder. Para êle, "todo o conhecimento do mundo social é um ato de construção [...] que deve se constituir contra as representações parciais e interessadas". ${ }^{3}$

\section{2 - Campo artístico}

A Constituição de um campo artístico para Bourdieu ocorre quando há uma progressiva autonomização do sistema de relações de produção, circulação e consumo de bens simbólicos, que se estabelece como um sistema de relações objetivas, definindo-se em oposição aos campos econômico, político, religioso e às instâncias que tem pretensões de legislar a esfera artística. ${ }^{4}$

O processo de autonomização da produção artística é paralelo à constituição da categoria de artistas profissionais distinta, que não aceita as regras firmadas pelos artistas que os precederam e propõe novas condições para liberar a arte da dependência de campos não culturais. "O campo artístico enquanto tal significa o local da arte enquanto arte" ${ }^{5}$

O processo de autonomização exige do artista uma nova função para si e a sua obra. Bourdieu exemplifica com o Renascimento, momento histórico de formação do campo artístico, que permite aos artistas legislarem com exclusividade o seu próprio campo. Poder-se-ia mencionar que a criação de tratados de arquitetura, pintura, escultura por Alberti, Leonardo da Vinci e a construção de um novo classicismo formalizam os príncipios internos ao campo. ${ }^{6}$

O processo de autonomia do campo artístico é interrompido com a Contra-Reforma e as monarquias absolutistas, visto que a Igreja e o Estado passam a interferir novamente na prática artística.

A busca de autonomia é retomada no século XIX, quando os artistas românticos reagem à Revoução Industrial e ao mercado de arte, declarando a superioridade da arte. O seu posicionamento é fortalecido a partir da falência do discurso filosófico em atingir o absoluto e da atribuição à arte desta função pelos pensadores românticos. Eles defendem assim a sacralização da arte e os artistas afirmam a sua singularidade e a sua irredutibilidade ao estatuto de simples mercadoria. Segundo Bourdieu, é em oposição aos campos não culturais que surgem as teorias "puras" da arte. Essas instauram "a dissociação entre arte como simples mercadoria e arte como pura significação", " fato que permite também reafirmar a singularidade da condição artística e separar o artista do público.

Bourdieu acrescenta a esse processo de autonomização o fato de que a ruptura de dependência em relação ao mecenas e às encomendas diretas propicia ao artis-

3 BOURDIEU, P. La distinction. Paris: Minuit, 1979. p. 544-5.

4 Os principais conceitos sobre campo, autonomia e sistema de relações sociais no interior do campo basearam-se no texto "O mercado de bens simbólicos". In: Economia das trocas simbólicas. São Paulo: Perspectiva, 1974.

5 BOURDIEU, P. Règles de l'art. Paris: Seuil, 1992. p. 310.

6 Deve-se destacar que é no Renascimento que é definida a posição social do artista, diferenciando-a do artesão. $\mathrm{O}$ artesanato foi a atividade com a qual a arte esteve vinculada durante a Idade Média.

7 BOURDIEU, P. "Mercado de bens simbólicos". p. 103. 
ta uma liberdade que rapidamente é percebida como formal, já que este tem que se submeter às leis de mercado de bens simbólicos. As novas relações sociais que são estabelecidas caracterizam-se pela impessoalidade, levando o artista a se afastar progressivamente do público.

No século XIX, na França estrutura-se o campo da produção erudita e o campo da Indústria Cultural, cujas funções são estabelecidas no interior do primeiro e pelas leis de mercado, no último. O campo artístico configura-se como um dos campos da produção erudita que produz bens simbólicos destinados a um público de produtores de bens culturais; enquanto a Indústria Cultural é dirigida aos nãoprodutores, isto é, o grande público. Segundo Bourdieu, o campo da produção erudita tende a elaborar as suas normas, os critérios de avaliação de seus produtos e a lei de concorrência pelo reconhecimento cultural, concedido ao artista pelos seus pares, que são também clientes e concorrentes. As leis que regulam objetivamente as relações sociais tendem a se constituir em normas explícitas. Caso elas não sejam seguidas, o artista poderá sofrer a "exclusão simbólica", ${ }^{8}$ isto é, a rejeição de suas obras em salões, bienais, exposições, etc. Os princípios internos ao campo são criados em oposição aos externos, sendo os primeiros considerados face às demandas externas: sociais, econômicas e políticas.

A autonomia do campo artístico pode ser avaliada pelo papel que o crítico de arte exerce, com vistas a fornecer uma interpretação das obras de artistas que se distanciam do público, ao utilizarem os principios da teoria "pura". A crítica de arte reforça este afastamento, porque intermedia o contato entre estas duas instâncias e desenvolve discursos herméticos que são em geral compreendidos apenas pelos seus pares.

Artistas, críticos de arte, teóricos e historiadores constituem, segundo Bourdieu "sociedades de admiração mútua" ou "seitas fechadas", ${ }^{9}$ já que as obras são legitimadas, consagradas e consumidas entre prociutores de cultura. Às vezes, os escritores atuam como críticos de arte, como por exemplo, Emile Zola, Baudelaire e Apollinaire, militando em prol de novas concepções e práticas artísticas e reforçando um "esprit de corps" que resiste às tradições canônicas. A crítica de arte cria as "condições de nova crença, capazes de dar um sentido à arte" neste mundo que é o universo artístico. ${ }^{10}$

Para Bourdieu, o fechamento do campo a partir do estabelecimento de normas internas, de teorias "puras" e do monopólio da consagração do artista revelam um certo temor de intervenção do grande público. Enfim, todos esses mecanismos são criados com o objetivo de evitar a interferência de outros campos não culturais.

O campo funciona ainda como espaço de competição para a legitimidade cultural, fenômeno que gera a busca de distinções culturais, isto é, de temas, técnicas e estilos que são dotados de valor, na medida que os grupos que os produzem são reconhecidos culturalmente, atribuindo-lhes marcas de distinção: especialidade, maneira, estilo. Essas marcas são reconhecidas no campo pelas taxionomias culturais disponiveis. Bourdieu exemplifica com um texto de Proudhon, o qual apresenta

\footnotetext{
8 Idem, p. 106.

9 Idem, p. 107.

10 BOURDIEU, P. Règles de l'art. p. 195.
} 
as diferentes especialidades dos artistas: pintores de igreja, de história de batalhas, de marinhas, retratos, etc.; cada artista destaca-se na sua especialidade. Para ele, é a própria lei do campo que envolve os artistas na busca da distinção e é ela que impõe também os limites para que a mesma seja um exercício legítimo. "As lutas de definição ou classificação tem o fim de estabelecer fronteiras entre os gêneros [...] e daí as hierarquias"; sendo um dos mecanismos utilizados para a defesa da ordem no interior do campo. ${ }^{11}$

O campo só afirma a sua autonomia quando controla a distinção cultural, valorizando sobretudo a forma sobre a função e o sistema de representação sobre o objeto representado. A luta pela independência do campo é paralela às pesquisas estéticas que libertam a arte do tradicional sistema representativo, oriundo do Renascimento, e que se orientam na busca de suas especificidades e de sua essência. "O monoteísmo incarnado na Academia cede lugar à concorrência de múltiplos deuses incertos". ${ }^{12}$

O processo de circulação e consumo - dominado pelas relações objetivas entre às instâncias e os agentes - constitui-se no sentido público da obra, pelo qual o artista é definido e em relação ao qual ele é obrigado a definir-se. As relações sociais em que se concretiza o sentido público da obra, são aquelas que se estabelecem entre o artista e o crítico, o curador e o museólogo. Estas relações são comandadas pela posição que tais agentes ocupam na estrutura do campo da arte (artistas mais conservadores mantém relações com críticos mais conservadores), e definidas pela posse do poder simbólico. Portanto, é no processo de recepção que o artista assume uma determinada representação, condicionada ao tipo de consagração.

Os princípios internos do campo artístico sofrem mudanças à medida que se reproduzem rupturas em relação aos modos de expressão anteriores. $\mathrm{O}$ artista moderno exclui as referências externas ao campo, mas reavalia constantemente os principios internos do mesmo, tendo assim o fim de manter as suas especificidades e regras. No entanto, as instâncias do sistema de ensino do campo artístico, segundo Bourdieu, não acompanham as transformações sofridas na arte, assegurando a reprodução de sistemas de representação artística mais tradicionais contra concorrentes heréticos. A Academia francesa, no século XIX, para preservar os seus cânones tem a necessidade de contar com alguma heresia externa para combater.

O sistema de ensino cria uma certa defasagem entre a arte praticada e a educação artística, sendo essa banalizada e racionalizada por necessidades de inculcação. Para Bourdieu, a banalização seria o processo de tornar banal e cotidiano os esquemas perceptivos e de apreciação dominados pelo público intelectualizado. ${ }^{13}$ O sistema de ensino trata, assim, de contribuir para a decodificação de esquemas perceptivos em desuso. Poderia-se acrescentar que o sistema de museus reforça o sistema de ensino, ao expor geralmente obras do passado.

11 Idem, p. 313.

12 Idem, p. 191.

13 O conceito é oriundo de Max Weber de cotidianização. In: BOURDIEU, P. "Mercado de bens simbólicos", p. 123. 
Para Bourdieu, o campo caracteriza-se ainda como espaço no qual as posições dos agentes se encontram a priori fixadas, porque este se constitui em dois pólos: dominantes e dominados. Dominantes são os agentes que têm o seu capital simbólico reconhecido; e dominados são aqueles em que há ausência ou menor capital simbólico. ${ }^{14}$

No campo artístico, os dominantes possuem o poder de legitimação dos bens simbólicos, detendo desta forma o poder de estabelecer uma ordem e um sentido ao mundo social. Eles são dotados de autoridade para consagrar e revelar as novas concepções de arte, desfrutando uma posição hierárquica reconhecida. Portanto, o poder simbólico não reside nos sistemas simbólicos e nem é arbitrário, mas se define numa relação social determinada na própria estrutura do campo. ${ }^{15}$

As estratégias dos agentes orientam-se de acordo com a posição que eles ocupam no interior do campo. Ao pólo dominante correspondem práticas ortodoxas que têm em vista preservar o capital simbólico; enquanto ao pólo dominado correspodem as práticas heterodoxas que buscam desacreditar os detentores reais do capital legitimado. Os dominados utilizam estratégias para subverter a hierarquia institucionalizada, o que implica no confronto permanente. Estas estratégias, para Bourdieu, destinam-se à socialização e à criação de novas crenças. ${ }^{16}$ No entanto, a contestação do poder não coloca em questão os princípios que estruturam o campo da arte. Para ele, a ortodoxia necessita da heresia porque a sua imposição implica em reconhecimento, permitindo assim a continuidade do campo. ${ }^{17}$

As relações de poder no interior do campo reproduzem, segundo o sociólogo, as relações que lhe são externas, entre dominantes e dominados e as produções artísticas servem as duas posições sociais. Para ele, há uma homologia entre a distribuição de produtos culturais no mercado e a posição social. A partir desta constatação, ele afirma que existe uma relação mais estreita entre capital simbólico e capital econômico. ${ }^{18}$

Bourdieu concebe as relações sociais como relações de poder, visto que estas reproduzem o sistema de dominação interiorizado pelos agentes sociais. Para ele, a reprodução da ordem não é originária apenas dos aparelhos coercitivos do Estado como pensava Althusser ou das ideologias oficiais, mas se inscreve em niveis mais profundos, atingindo inclusive as escolhas estéticas. ${ }^{19}$

A sua noção de poder fundamenta-se em parte na noção de habitus, retomada por Bourdieu da escolástica medieval, a qual concebe que os hábitos precocemente transmitidos pela educação, sobretudo familiar, se constituem em condutas profundamente arraigadas através da repetição, capazes de engendrar ações previsiveis. ${ }^{20}$ O habitus significa esta capacidade adquirida socialmente pelo indivíduo de esta-

14

15

16

17

18

19

20

BOURDIEU, P. "Sobre o poder simbólico". In: O poder simbólico. Lisboa: Difel, 1989. p. 11-14.

Idem, p. 14.

ORTIZ, Renato. "A procura de uma sociologia da prática". In: Pierre Bourdieu. São Paulo: Ática, 1983. p. 22-23.

BOURDIEU, P. Libre - échange. Paris: Seuil, 1994. p. 57.

BOURDIEU, P. Règles de l'art. p. 238.

ORTIZ, R. op. cit., p. 26.

DUBAR, Claude. "Bourdieu". In: Dictionnaire encyclopédique de l'éducation et de la formation. Paris: Nathan Université, 1994. p. 127. 
belecer as suas relações de forma objetiva e sem a necessidade de reflexão premeditada. Daí a reprodução da ordem ser objetiva e subjetiva ao mesmo tempo, visto que 0 agente pode revesti-la aparentemente de um caráter pessoal. "Os esquemas de habitus devem a sua eficácia pelo fato deles funcionarem à despeito da consciência e do discurso, portanto fora do exame e controle voluntário". ${ }^{21}$ É a partir do conceito de habitus que Bourdieu estabelece a articulação entre o agente individual e o grupo social, sendo assim de extrema importância para o estudo objetivo da arte.

O sociólogo relaciona a noção de habitusao retomar o conceito de gosto de Kant, como uma disposição que se adquire para "diferenciar" e "apreciar", isto é, para marcar as diferenças por uma operação de distinção. O habitusfunciona nesta circunstância independente da consciência e do controle voluntário. ${ }^{22}$

Bourdieu analisa ainda o conceito de "gosto puro" de Kant, mostrando como este é recorrente nos discursos sobre arte, com o fim de esclarecer que o mesmo é outro mecanismo de afirmar a distinção social, já que se fundamenta no princípio do prazer desinteressado, sendo assim oriundo do refinamento. Este opõe-se ao prazer vulgar, o qual se vincula à finalidade da obra de arte e a um tipo de gosto grosseiro. ${ }^{23}$ Comprovando estes pressupostos através de pesquisas empíricas, ele demonstra que os diferentes tipos de prazer são condicionados pelo habitus. ${ }^{24}$

\section{3 - Considerações gerais}

O arcabouço teórico desenvolvido por Bourdieu para o entendimento do sistema de relações entre as diferentes instâncias, da prática artística à recepção e à comercialização do objeto, permite novas abordagens nos domínios da História da Cultura e da Arte, conduzindo os estudiosos a revisarem certas hipóteses concebidas como já solucionadas, sobretudo no que se refere ao Renascimento italiano. A articulação entre as ações individuais e os agentes sociais colaborou para o estudo mais objetivo da arte, visto que a História da Arte desde Vasari se peculiariza por ser uma História de Artistas, e mais recentemente, a partir de Wolfflin, uma História de Formas. Aby Warburg, Erwin Panofsky e Pierre Francastel criam novos métodos de estudo das artes plásticas, com vistas a terminar com as análises parciais e reducionistas; sendo que o último desenvolve os fundamentos da sociologia da arte. ${ }^{25}$ No entanto, Bourdieu ao criar os conceitos de campo de arte, autonomia, habitus, e estudar o sistema de relações sociais internas e externas ao campo, estabelece um quadro de referência teórica mais amplo que permite a análise da arte em todas as suas instâncias sociais.

21 BOURDIEU, P. La distinction. p. 543.

22 Idem, p. 543.

23. Idem, p. 576.

24 No livro L'Amour de l'art. Bourdieu e os dois outros colaboradores fazem uma grande investigação sobre o tipo de público que frequenta os museus de arte, servindo como subsídios para a construção de seu pensamento social.

25 O método de análise de Francastel não se limita à sociologia, peculiarizando-se também por enveredar nos domínios formal do objeto e da estética. 
Os historiadores da arte ao se apropiarem do suporte conceitual e metodológico de Bourdieu procuram fazer a análise interna do objeto, isto é, de ordem formal, paralela às considerações sociológicas, estabelecendo as ligações e condicionantes entre o fazer artístico e o sistema de relações sociais.Este procedimento não é, em geral, de interesse do cientista social.

Observa-se a adoção de conceitos de Bourdieu sendo aplicados também pelos estudiosos de estética, condicionando-os a buscarem a explicação de certos fenômenos no plano social. ${ }^{26}$ Esta interdisciplinaridade tem possibilitado abordagens extremamente mais ricas e conduzido os pesquisadores a novos conhecimentos.

Bourdieu no livro "Coisas ditas" afirma que é necessário levar em conta além do campo, a análise interna da obra em particular e a sua intertextualidade, isto é, o seu relacionamento com o conjunto de obras. Para ele, a leitura da textualidade da obra pode ser executada via intertextualidade, através do sistema de desvios pela qual ela se situa face às obras contemporâneas. Ele demonstra que esta leitura da obra deve ser feita de modo inseparável da apreensão estrutural do artista. ${ }^{27}$ Percebe-se, assim, nos seus estudos o maior interesse por aqueles artistas que produzem obras singulares e desta forma geram desvios face às concepções estéticas vigentes. ${ }^{28}$ Nestes casos, ele considera os fatos que conduzem às rupturas, podendo os mesmos serem de ordem extra-artística: moral, social,etc. A questão formal não chega a ser abordada.

O sociólogo francês ao construir um pensamento social crítico com vistas a tornar os fenômenos sociais transparentes, demonstra buscar aliar a sua condição de cientista com a conduta militante, que tem caracterizado a sua trajetória. Frente à esta postura pessoal, percebe-se na produção intelectual de Bourdieu uma certa preferência pelo artista militante, ficando esta mais evidenciada em "Libre-échange", livro publicado juntamente com o artista alemão Hans Haacke. ${ }^{29}$

No diálogo que se formaliza entre o cientista social e o artista plástico, Bourdieu identifica este último como o agente social capaz de enfrentar as elites dirigentes e de subverter os meios de comunicação, sobretudo os jornalistas que têm colaborado para a comercialização da produção cultural. Apesar do sociólogo depositar as suas esperanças nesta categoria profissional, ele tem plena consciência das suas limitações de militância, quando demonstra que a mesma se une no momento em que a autonomia do campo é ameaçada.

Quanto à aplicação de seus conceitos e aportes teóricos para a pesquisa da História da Arte no Rio Grande do Sul, observa-se algumas dificuldades, face principalmente à questão da autonomia do campo artístico e de sua constituição.

26 SCHAEFFER, Jean-Marie. L'Art de l'âge moderne. Paris: Gallimard, 1992.

BOURDEUU, P. Coisas ditas. São Paulo: Brasiliense, 1990. p. 42.

Edouard Manet é o artista plástico mais focalizado pelo sociólogo graças os desvios produzidos face aos pricipios acadêmicos. Vide Règles de l'art, op. cit.; "L'institutionalisation de l'anomie" In: Les Cahiers du Musée National de L'Art Moderne, junho 1987, p. 6-19; Coisas ditas, op. cit.

29

Vive em Nova Iorque e tem se notabilizado por produzir instalações, nas quais emite juizos criticos contra o Estado e as elites dirigentes norte-americanas e alemães, assim como denuncia a dependência de certos museus às estratégias conservadoras de alguns senadores e do Estado. Haacke estabelece, assim, uma crítica pública ao sistema de relações sociais interno e externo ao campo, fato pouco comum entre os artistas. 
Bourdieu mesmo demonstrando que a autonomia é relativa e que existe uma certa dependência em relação a outros campos, não menciona casos como o do Rio Grande do Sul, cujo campo artístico tem se peculiarizado pela constante fragilidade. ${ }^{30}$ Deve-se destacar ainda que o campo só começa a se formalizar nos anos 50, quando emerge o sistema de relações entre as instâncias de produção, circulação e consumo. Como aplicar os métodos de análise do campo artístico nas décadas que antecedem a sua constituição? Como aplicar a taxionomia do gosto puro e do gosto vulgar, quando as esporádicas exposições de arte apresentam conjuntamente objetos oriundos de cópias, industrializados e de arte? Muitas décadas da História da Arte do Rio Grande do Sul ficam a descoberto, sendo necessário se repensar a metodologia mais adequada a ser utilizada, porém sem esquecer de se levar em conta os problemas específicos a serem tratados.

Se por um lado, o suporte conceitual de Bourdieu é extremamente significativo; por outro, não se pode deixar de estabelecer um diálogo constante com o objeto de arte, pois ele não é uma mera ilustração dos modos de vida social de uma época. A sua gênese é mais complexa e as suas motivações podem ser de naturezas diversas, fenômeno que possibilita múltiplas leituras do mesmo. Assim, a análise formal do objeto de arte aliada a um olhar antropológico e histórico, isto é, "um olhar atento às condições de existência, de uso e de apresentação das formas analisadas, ${ }^{31}$ pode nos conduzir a uma outra leitura. Nenhuma invalida a outra.

30 As instituições de arte em geral não possuem regulamentos próprios; sofrendo a cada mudança de direção e govemo interferências nos seus programas e rumos, além dos problemas de ordem financeira que têm conduzido à deterionização das mẹsmas.

DDI-HUBERMAN, G. Le cube et le visage. Paris: Macula, 1993. p. 212. 